\title{
Life Cycle Assessment of Low Temperature District Heating System in Gulbene Region
}

\author{
Fabian DIAZ ${ }^{1 *}$, Ieva PAKERE ${ }^{2}$, Francesco ROMAGNOLI ${ }^{3}$ \\ ${ }^{1-3}$ Institute of Energy Systems and Environment, Riga Technical University, Azenes iela 12/1, \\ Riga, LV-1048, Latvia
}

\begin{abstract}
New district heating system technologies have arisen in the last years to deliver economic and environmental benefits to residential and commercial buildings. The extensive ranges of equipment, energy sources, temperature profile configurations, size of the network, energy demand, and many other intrinsic variables, make it difficult to identify if a determined district heating option is potentially better than another in environmental terms. As for the economic evaluation, there are several tools decision-makers can rely on to assess environmental performance. The main challenge is to provide a holistic point of view for which lifespan and complexity of implementable, new technological systems can be an obstacle. For this reason, in this paper, a Life Cycle Assessment is performed upon a technical evaluation of several district heating configuration options for the Gulbene region in Latvia, where DH systems in most of the assessed parishes are already operating under medium temperature regimes, also known as third-generation district heating. The goal of the study is to understand the environmental impact of moving from the current DH system to a low temperature one. Results show a considerable environmental benefit if low-temperature profiles, combined with the use of renewable energy sources are adopted in the current DH systems. A hotspot analysis is also performed showing the use stage is the one carrying most of the burden across the project's lifetime, followed by infrastructure construction; also showing that the refurbishment of buildings does not play a major role in the total environmental impact contribution.
\end{abstract}

Keywords - Central heating; energy strategy; environmental impact; IMPACT 2002+, ISO 14044, sustainable development

\author{
Nomenclature \\ GHG Greenhouse gases \\ LCA Life Cycle Assessment \\ LCI Life Cycle Inventory \\ LCIA Life Cycle Impact Assessment \\ 4GDH Fourth Generation District Heating \\ 3GDH Third Generation District Heating \\ LTDH Low Temperature District Heating \\ PES Pilot Energy Strategy \\ APOS Allocation at the Point of Substitution \\ Pts The average impact in a specific category caused by or upon a person for one year
}

* Corresponding author.

E-mail address: Fabian-andres.diaz-sanchez@rtu.lv 


\section{INTRODUCTION}

District heating (DH) systems can provide heat supply to communities various in size from a small parish or community to whole cities. Although the most important aspect is selecting an energy source that delivers a higher cost-benefit than a conventional boiler or electric heating system [1], in this view the environmental aspect is a fundamental part to follow. For Latvia specifically, it is stated under the "Sustainable Development Strategy" goals [2] that a renewable and safe energy system must be reached by 2030 to include a $50 \%$ of Renewable Energy Source (RES) share in the final energy consumption by implementing energy policies. Similar paths have been followed by many European countries in the last decade, where DH systems have evolved towards more sustainable systems [3].

In 2014, Connolly et al. [4] designed a heat strategy capable of reducing heating and cooling costs by $15 \%$ in 2030 and 2050 by using the renewable heat potential in district heating systems. The study, among others, compared the costs and $\mathrm{CO}_{2}$ emissions of their new energy strategy with the EU scenario of reference in the "European roadmap 2050" [5]. It was concluded that district heating is a vital technology for decarbonization paths in the EU energy system and should be considered. It has also been determined that further studies and research on district heating systems should focus on the policies and technological routes necessary to achieve economic and technical feasibility to successfully transition towards sustainable district-based systems [6]. These sustainable DH systems include not only the use of RES but also using low-temperature profiles in the DH distribution network. Conventional DH systems as they are known today, work within a wide range of temperature profiles for their supply and return lines (from $90{ }^{\circ} \mathrm{C}$ to $50{ }^{\circ} \mathrm{C}$ ) [1]. On the other hand, low-temperature district heating (LTDH), also known as fourth generation district heating (4GDH) systems, works in the range of $50-20^{\circ} \mathrm{C}[1]$.

It has been proved that $4 \mathrm{GDH}$ systems can reduce energy losses, balance renewable energy in electricity grids, use industrial excess heat that is usually eliminated by cooling technologies or released to the environment, and has powerful economic potential when implemented correctly [7]. There is the Swedish case, where Sernhed et al. (2018) [8], explain how despite Sweden's DH system is almost fossil-free, the next challenge is to give use to low-temperature heat sources. They uncovered that the current DH technology needs a long-lasting modification to allow better utilization of renewable, recycled, stored, and waste heat [8]. Moreover, in 2017 Vigars et al. [9] showed the benefits in operational terms, which equipment in the DH system could obtain from working with network low temperatures return lines increasing their efficiency. Mathematical models to forecast and understand new equipment behaviour under reduced DH network temperature operation, have been already developed and tested successfully, proving again the benefits 4GDH technologies [10].

Implementing the essential modifications to DH systems and to the system structure and buildings, where the source of the thermal energy demand is generated, will carry an environmental burden that needs to be assessed. Studies addressing the bottleneck of heat production infrastructure challenges, and storing capacities, have already been undertaken [11]. However, the environmental toll of transitioning towards the analysed 4GDH has not been captured. A similar issue is found in the research made by Curtis et al. (2018) [12] where it is stated that the proximity to the thermal production facility is the most important factor in determining the $\mathrm{DH}$ upgrade in a residential area, whereas the environmental impact is disregarded. Due to the lack of holistic approaches considering sustainable development goals, it becomes necessary to implement methodological studies able to calculate the environmental impact of new 4GDH systems. By including within the 
scope, all the activities related to infrastructure preparedness and construction, and the operational phase which involves not only the raw materials or fuel required to run a $\mathrm{DH}$ system but also the background processes contained in it and expanding the boundaries to also assess the expected changes in the residential and commercial buildings under different scenarios, the goal of fully assessing the environmental impact of these new 4GDH systems is settled.

\section{Life CyCle Assessment Methodology}

One of the main motivations for the developing of new DH systems is the resulting environmental benefits, as such systems can reduce greenhouse gases (GHG) emissions, air pollution, ozone depletion, and acid precipitation among other advantages, by integrating RES, improving efficiency in equipment and moving from individual solutions to central heating systems. From the sustainable development point of view, DH systems are understood as a service, which makes it necessary to quantify the environmental impacts arising from it, since it is created and used to fulfil a need. All products (goods or services) have a life cycle, beginning with design, development, resource extraction, production (here there may exist several production phases, manufacturing of materials required for later production of the analysed product, transformation of raw materials, energy production, etc.), use or consumption, and the end of the life activities (collection, sorting, reuse, recycling, and waste disposal) [13]. The concatenation of all these activities along the life cycle results in environmental impacts due to resource consumption, emissions of substances into the environment, and some other environmental exchanges such as radiation or ionization.

Life Cycle Assessment (LCA) is recognized as the most powerful and widely used tool for undertaking holistic environmental sustainability assessments, as it is capable of assessing the product's environmental impacts from cradle to grave [14] on a multicriteria approach. The principle is to compute the materials and energy flow inputs and the emissions at all phases (stages) in the life cycle of a production process. LCA offers a broader perspective because it can be utilized to evaluate a wider range of environmental impact categories, beyond climate change, which is often the usual and only parameter considered when assessing environmental performance, particularly for energy production and distribution scenarios. One of the advantages of LCA is complementing local environmental impact assessments by analysing the impacts from a global perspective, therefore avoiding the so-called "burden-shifting" [15]. As a result, LCA is understood as a methodological framework to estimate the environmental impacts coming from the life cycle of a determined product. Such impacts can be classified in climate change, stratospheric ozone depletion, tropospheric ozone creation (smog), eutrophication, acidification, toxicological stress on human health and ecosystems, resource depletion, water use, land use, noise, and others [16].

Methodologies to implement an LCA vary among studies, but the most common one remains to be the LCA ISO standard 14040 and 14044. The ISO 14040 (1997) describes the principles and framework for LCA while ISO 14044 presents requirements and guidelines to perform the assessment. According to the framework found in ISO 14040, a complete life cycle, with its associated material and energy flows is called a product system. Then, collecting, tabulating, and performing a preliminary analysis of emissions and resource consumption is called Life Cycle Inventory (LCI), and most of the times it is necessary to calculate and interpret indicators of the potential impacts associated with the exchange of such flows with the natural environment, thus, performing a life cycle impact assessment (LCIA). 
In ISO 14044, the main four steps included in the LCA methodology are described: goal and scope, life cycle inventory, life cycle impact assessment, and life cycle interpretation [17]. Defining the goal and scope is the first step in an LCA, the objective is to make clear why the LCA methodology is performed and which phases of the production processes are analysed. Due to the iterative LCA nature, the scope is susceptible to redefinitions during the study. The goal and scope must define the intended application, the product system, functional unit (FU), system boundaries, LCIA methodology, assumptions and limitations, and some other data requirements. The second step is the LCI, where inventory is gathered and quantified according to the defined FU. In this step, the stages and the data collection and calculation techniques are described in detail. The third step, the LCIA, includes the collection of indicator results for the different impact categories, which together represent the LCIA profile for the product system. Such results are categorized in the aforementioned impact categories. It is at this point, where sensitivity analysis can be performed to determine how changes in data and methodological choices may affect the results. Finally, in the Life Cycle Interpretation, several elements are considered: identification of significant issues based on results, evaluation of consistency and sensitivity checks, and discussion of conclusions, limitations, and recommendations.

The LCA methodology has already been used in evaluating the environmental impact of district heating solutions in the past. In 2009, Oliver-Sola et al. [18], analysed the DH system's infrastructure in a neighbourhood using the Ecoinvent database and Gabi software finding that the main impacts are located in the power plants and dwellings instead of in the pipeline network. However, this study lacked heat consumption and losses during the use phase stage. In 2017, LCA studies conducted by Bartolozzi et al. [19], showed significant reductions in GHG emissions when renewable energy sources (RES) are integrated into heating and cooling alternatives, versus traditional individual systems. Using comparatives LCA on different DH systems as a decision-making tool has also been done under the life cycle management approach (LCA plus Life cycle costing) by Ristimaki et al. [20]. In their study, four DH systems scenarios were evaluated and the one with the best environmental score turned out to be the most viable in economic terms and carbon emissions reduction, despite being the one with the highest initial investment. Many other studies can be found in the literature, where the energy production phase of DH systems using different energy sources including RES are compared with conventional ones. In the case study covered in this project, a holistic approach is intended by evaluating in the long term, the environmental impact of infrastructure, and the use phase of DH systems as a decision-making tool.

Following the LCA methodology recommended by ISO 14044, the selected method for processing and present the results was IMPACT 2002+. This method offers several advantages versus classic impact assessments-oriented ones such as EDIP or CML, where the outputs are arranged in midpoint categories using characterization factors, which restrict the quantitative model to relatively early stages in the cause-effect chain, and also when compared to only damage oriented methodologies such as ReCIPe or Eco-indicator 99, where the cause-effect chain is quantified by the model using endpoint characterization factors. IMPACT 2002+ merges the advantages of both schools of methodologies, by grouping analogous category endpoints and building a set of damage categories, but also using midpoint categories, with each one of them related to one or more damage categories [21]. 


\section{LCA CASE STUdY}

Gulbene region comprises the city Gulbene and 6 parishes that nowadays have the installed district heating systems working under what can be called third-generation technology that is also the state of the art for more of the district heating systems currently working in Northern and Eastern Europe. Nevertheless, while seeking to meet the aforementioned plans, Gulbene region has started to work towards a more energy-efficient performance by the development of a Low Temperature District heating network, initially implemented in the Belava parish [22]. Under the Pilot Energy Strategy (PES) for Gulbene region, the 6 parishes including Gulbene municipality have been considered for developing low-temperature or also called fourth generation district heating (4GDH) systems, and initial studies assessing technical and economic feasibility have already been structured for different future scenarios [23]. However, the environmental load of probable future scenarios should be analysed and compared to the current heat production and distribution practice, to quantify the impact change in different areas of concern from those different proposed options for development.

\subsection{Goal and scope definition}

\subsubsection{Goal}

The goal of this study is to assess the environmental impacts of the baseline scenario for the current DHS in Gulbene region and a possible future scenario where temperature profiles in the distribution network are lowered, basically due to insulation improvements in the buildings, as part of a new Low Temperature District Heating system (LTDH).

The main objective of the project is to show the effects of moving towards transition from a $3 \mathrm{GDH}$ system to a $4 \mathrm{GDH}$ system. The LCA study will provide, in junction with an economic assessment, a reliable decision-making tool providing consistent thresholds for the section of the optimal technological solution in line with "Latvia's Sustainable Development Strategy $2030 "[2]$.

\subsubsection{Scope}

The scope requires a clear description of the function and functional unit, system boundaries, methodology, and data requirements in order to sufficiently address the stated goal. As said before, an attributional model is performed for this study to evaluate the environmental load of the DH system baseline scenario with the proposed upgrade to an $4 \mathrm{GDH}$ future scenario. The timeframe of the study only includes existing technologies and described technologies in this project. Hence, the effect of new technologies will not be taken into consideration. Future trends in insulation improvements across the pipelines that comprise the distribution network, resulting in heat loss reductions, or in the boiler house, are also not considered other than those explicitly discussed within the project.

Among the different scenarios comprised in [23], some of them evaluate not only the reduction in the temperature profile across the network but also the inclusion of new customers, decoupling of some buildings while maintaining the same temperature profile for the supply and return lines of the DH network. Within this study, only scenarios falling under the definition of 4GDH were analysed and compared to the baseline one.

For the baseline scenario, the current technology, data for calculations, fuels and networks described in [23] were used for modelling activities as part of the background data. Foreground data was obtained from [22] and then it was assumed that similar infrastructures are encountered or developed in the other Gulbene parishes. The distribution network 
temperature is usually assumed as $70{ }^{\circ} \mathrm{C}$ for the supply pipelines and $45^{\circ} \mathrm{C}$ for the return lines, although each parish has its own temperature schedule.

The LCA performed in this project was completed using Simapro 9.0 software integrated with Ecoinvent 3.0 database.

\subsubsection{Functional unit}

A functional unit (FU) is a measure of the performance of the functional outputs of the product system and its primary purpose is to provide a reference to which the inputs and outputs are related. This reference is necessary to ensure the comparability of LCA results. The definition of a functional unit must hence include both the quantitative and the key qualitative aspects to avoid subjectivity when subsequently defining an equivalence.

In this case, the functional unit is the operation and maintenance of the DH system over an assumed time horizon for delivering the required heat demand of the different Gulbene parishes and the municipality including infrastructural works required for heat distribution in each scenario. This includes any construction or renewing work required either for the baseline or future scenarios, such as boiler house construction or maintenance, the deployment of required new pipelines and heat pump installation or refurbishment, and insulation materials for the customer's buildings.

\subsubsection{System boundaries}

The parishes under evaluation are located in north-eastern Latvia in the Vidzeme region and the heating season in Gulbene, in accordance with Cabinet Regulation No. 338 "Regulations on Latvian Construction Standard LBN 003-15 "Building Climatology", is 209 days in duration with an average outdoor air temperature of $-1.4{ }^{\circ} \mathrm{C}$ [23]. The duration of the heating season is based on the assumption that heating in the buildings is switched on when the average five-day outdoor air temperature is below $8{ }^{\circ} \mathrm{C}$ and accordingly switched off when the five-day average temperature is above $8{ }^{\circ} \mathrm{C}$.

The system boundaries comprehend the construction of boiler houses, including energy and raw materials required for all equipment and accessories, the transport of materials for construction, and the energy required for it. Within the assemblies for the boiler house, nodes, pumps, taps and DH pipeline networks, materials, and equipment susceptible to replacement during the lifespan of the project are also included. Construction of solar plants, heat pumps, accumulation tanks, as elements, energy, and processes required for their construction, are also considered.

As can be seen in Fig. 1, for the operational phase, the fuel and electricity required to run the boiler house, pumps, and other equipment is accounted, including the extraction and transport of fuels. Nevertheless, operations related to non-schedule maintenance and repairs are not included due to their intrinsic feature of uncertainty and to avoid overestimating impacts. The replacement of equipment such as recirculation pumps during the lifespan of the project, however, are considered. 


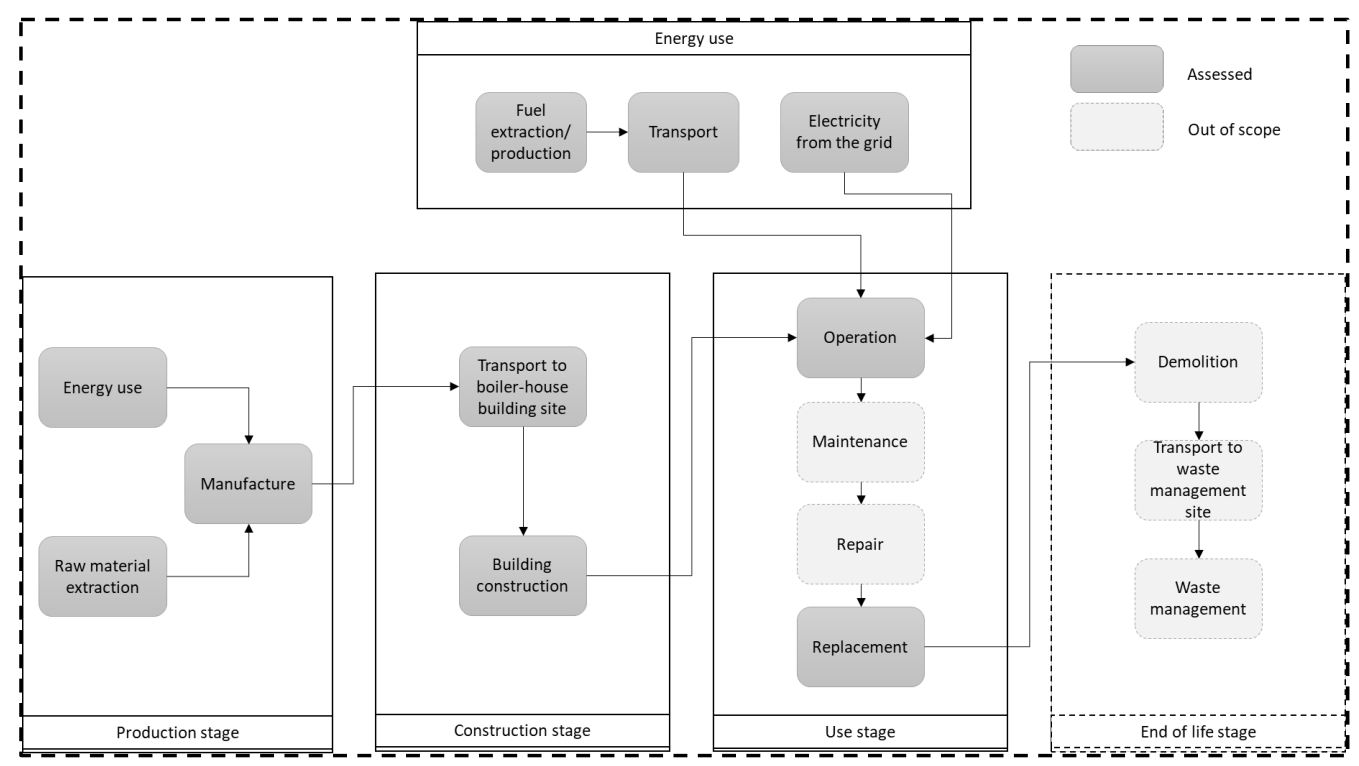

Fig. 1. System boundaries on the supply side.

The service life or intended time horizon is for 25 years from 2020, hence only available technologies at the moment of writing this document are considered within the study. The end of life stage is not considered at all in this study, as the useful life of a DH system depends on many variables such as governmental policies, the technological diffusion of new technologies, rate of change in population (demand side), and maintenance of the network and boiler house.

Regarding boundaries on the demand side, the approach for the residential or public buildings gate to grave perspective and only repair/replacement material and activities within the use stage are considered, as consumer buildings are already in operation, connected to a $3 \mathrm{GDH}$ system and all that is required for adopting a $4 \mathrm{GDH}$ system, is the essential refurbishment to reduce the specific heat consumption in terms of $\mathrm{kWh} / \mathrm{m}^{2}$ per year. As the useful life of a residential or public building can be even longer than the one for a boiler house, the end of the life cycle is also out of the boundaries of this study.

\subsubsection{Limitations and Assumptions}

Among the limitations that apply for all parishes and scenarios, the main one to consider is the technology deployed in them, as only those currently available at a commercial level are considered. Most data used for modelling was found in the Ecoinvent database 3.0, and decommissioning or waste treatment for baseline scenarios are not considered. Some materials used for the assemblies might account for waste scenarios and would be mentioned when it happens.

In order to account for the whole impact of the assembly and operation of the district heating network, construction materials, equipment, and raw materials are included for all scenarios, this means the construction phase is within the boundaries as described in [23]. Nevertheless, this construction phase and all activities and materials are subject to data availability, which is limited due to the fact that all future scenarios are only proposals at the time this study was made, so detailed plans for the reconstruction of the boiler house are not available. The 
distribution network, nodes, taps and pumps suffer from the same lack of information, as only basic data regarding pipeline length and diameter are available, hence, it was necessary to use the assembly data gathered in [23] for Belava parish, and use the same record for the modelled parishes in this study. This assumption is made since Belava is a parish within the Gulbene region and it is included in the Pilot energy strategy project.

For baseline scenarios:

- Only base load boilers are used.

- No changes in distribution network temperature profiles or $\Delta \mathrm{T}$ between supply and return lines.

- No changes in insulation technologies along the network, maintaining the same heat losses trends.

- After any equipment replacement or maintenance, and renovation, the same boiler technology is used, using the same fuel type and consumption rate.

- A low calorific value of 3.5 MWh/ton of woodchips is used for calculations.

- A boiler efficiency of $89 \%$ is used for the whole-time horizon [23].

- Calculations for the amount (tonne) fuel consumption was carried out considering previously mentioned values.

- No decommissioning phase was considered.

For 4GDH scenarios:

- Steady production and heat demand profile during the study lifetime.

- There are no changes in temperature profiles after the 4GDH system implementation.

- Steady production and heat demand profile during the study lifetime.

\subsection{Life cycle inventory (LCI)}

As the current DH infrastructure of each parish varies in terms of the type of boiler, fuel and furnace, and boiler size, the infrastructure data was taken from Belava parish [22] since this one was chosen as the Pilot development parish for assessing an 4GDH system in the Gulbene Region. The main boiler house structure, pipelines, DH nodes and other accessories such as valves, pumps and taps, were adjusted according to the size or length of each one described in [23] as long as actual detailed design engineering data for future renovation or refurbishment of these structures are not yet available and economic feasibility for most of the projects is still ongoing.

As described in the LCA of the Pilot energy strategy report for Belava, the data for common assemblies (pipelines, boiler houses, nodes and materials for building refurbishment) were gathered from certificates of manufacturers and then grouped into the corresponding material and processes within the Ecoinvent 3 database. Some DH assemblies have an equivalent input object in the Ecoinvent 3 database, but many do not. Such equipment, apparatus or accessories missing in the database, were entered as the amount and materials required for their production plus the process required to construct the assembly.

The whole inventory gathered for the LCA on the PES was divided into stages, for organization and conceptual purposes. For the construction stage, the main groups, basic for any DH system are pipelines, boiler house, DH nodes, pumps and accessories, furnaces, and accumulation tanks. Other assemblies were built for each parish and scenario model, such as solar plants, furnaces, accumulation tanks and containers (for small capacity pellet boilers when necessary). It must be mentioned that these groups only account for the production and construction stage (see Fig. 1) as selected objects from the Ecoinvent 3 database correspond to items allocated at the point of substitution (APOS). Thus, the use stage, including operation 
of the DH assemblies, and the energy use phase which contains the fuel extraction or production, transport to boiler house and electricity or other energy use, is part of another assembly within the model, named "operational phase" in this LCA model. The same approach was used for the user side, with the building refurbishment required for accepting low temperatures under the future $4 \mathrm{GDH}$ scenarios.

A general example of how the assemblies were designed for inventory input is shown in Table 1. The summary of stages/processes about a particular parish assembly which is modelled in Simapro is displayed in Table 2.

TABle 1. OPERATIONAL PHASE FOR STARI PARISH - 4GDH SCENARIO

\begin{tabular}{lcc}
\hline Materials or Assembly & Amount & Unit \\
\hline $\begin{array}{l}\text { Roundwood, parana pine from sustainable forest management, under bark }\{\mathrm{GLO}\} \mid \text { market for } \mid \\
\text { APOS, } \mathrm{U}\end{array}$ & 1194 & $\mathrm{~m}^{3}$ \\
\hline Processes & Amount & Unit \\
\hline $\begin{array}{l}\text { Heat, district or industrial, other than natural gas }\{\mathrm{CH}\} \mid \text { heat production, hardwood chips from } \\
\text { forest, at furnace } 300 \mathrm{~kW} \mid \mathrm{APOS}, \mathrm{U}\end{array}$ & 900 & $\mathrm{MWh}$ \\
Electricity, medium voltage $\{\mathrm{LV}\} \mid$ market for $\mid \mathrm{APOS}, \mathrm{U}$ & 23.1 & $\mathrm{MWh}$ \\
\hline
\end{tabular}

As can be seen in Table 2, assemblies such as DH pipelines, and nodes, are adjusted to the size or length of the specific parish taking as a base, the assembly inventory from Belava parish. The operational stage is entered considering [23], which contains the inventory of fuels and materials required for a year of operation under the scenario described in the previous section.

TABLE 2. STARI 4GDH SCENARIO MODEL

\begin{tabular}{ll}
\hline Material/Assemblies & Amount, pieces \\
\hline New Boiler House - No furnace & 1 \\
Old District heating Pipelines & 0.61 \\
DH nodes & 0.61 \\
Boiler pumps, taps, heat m., exch. \& flow device & 1 \\
Node pumps and taps & 0.61 \\
Pipeline pumps, taps, heat meters, exch., flow d & 0.61 \\
Stari 4GDH Scenario Op. Phase & 25 \\
Building renovation assembly & 2353.3 \\
Intermodal shipping container, 20 -foot $\{$ GLO $\} \mid$ market for $\mid$ APOS, U & 1 \\
Furnace, pellets, with silo, 300kW \{GLO\}| market for $\mid$ APOS, U & 0.83 \\
Hot water tank, 6001 \{GLO $\} \mid$ market for $\mid$ APOS, U & 2.1 \\
\hline
\end{tabular}

The inventory for building renovation assembly, comprehend the materials required for lowering the average specific heat consumption in a determined building from the current state, down to the desired one in order for the inhabitants to enjoy the same temperature comfort than achieved under the actual $3^{\text {rd }}$ generation $\mathrm{DH}$ system. The principle is simple, the better the insulation, the lower the heat permeability (or heat loss), resulting in a lower specific heat consumption per square meter. Typical materials for building refurbishments towards 4GDH, and their environmental impact when used in these projects, are listed in [24] 
[25] and [26]. The average specific heat consumption for each parish under study is found in [23], as well as the calculated specific heat consumption required for future low-temperature DH scenarios, having in mind the new temperature operational schedules in each one of them, which are close to $65-45{ }^{\circ} \mathrm{C}$ for supply and return lines respectively. In order to create a material inventory for the refurbishment activities in the potential buildings under a possible 4GDH future scenario, previous projects for building renovations in Latvia were researched, finding two with similar specific heat consumption values to those in Gulbene region $\left(125-180 \mathrm{kWh} / \mathrm{m}^{2}\right)$ [27].

A list of materials and amounts $(\mathrm{kg})$ required for the renovation of 1 square meter was created and then adjusted to the different parishes in the present model (i.e. assembly "Building renovation" in Table 2) considering two variables, the total heated area and the gap between its current and future or desired specific heat consumption, which is usually between $70-90 \mathrm{kWh} / \mathrm{m}^{2}$ for the modelled parishes. The assembly built to refurbish $1 \mathrm{~m}^{2}$ and holding a capacity to reduce the specific heat consumption in around $115 \mathrm{kWh} / \mathrm{m}^{2}$ is shown in Table 3 .

Other assemblies such as furnaces and accumulation tanks are entered independently and according to the foreground data found in [23]. Such assemblies, including the use stage (operational phase) and the building renovation one, encompasses the summary of the full scenario to model, as seen in Table 2. Therefore, information for each parish is elaborated in two tables, one for the baseline scenario and another one including the building refurbishment and changes to the DH system (4GDH scenario).

TABLE 3. BuILDing RENOVATION ASSEMBLy

\begin{tabular}{ll}
\hline Material & Amount, $\mathbf{~ k g} / \mathbf{m}^{2}$ \\
\hline Polystyrene, extruded & 0.62 \\
Adhesive mortar & 2.36 \\
Gypsum plasterboard & 5.80 \\
Glazing, double, U<1.1 W/m ${ }^{2} \mathrm{~K}$, laminated safety glass & 0.20 \\
Alkyd paint, white, without solvent, in $60 \%$ solution state & 0.34 \\
Stone wool & 51.36 \\
Epoxy resin, liquid & 9.68 \\
Glass fiber & 0.46 \\
Glued laminated timber, for indoor use & 0.01 \\
Orthophthalic acid based unsaturated polyester resin & 0.06 \\
Steel, chromium steel $18 / 8$ & 0.04 \\
Soil for construction & 64.46 \\
Sand & 11.49 \\
Polystyrene foam slab for perimeter insulation & 1.22 \\
Concrete, normal & 0.04 \\
Acrylic filler & 0.44 \\
Ceramic tile & 0.19 \\
\hline
\end{tabular}




\subsection{Life Cycle Impact Assessment and Interpretation}

The LCI gathered was used for the simulation in Simapro in accordance with the defined functional unit. The following results are presented in a comparative way for the baseline and for the proposed 4GDH scenarios. First, the environmental impact assessment is presented at midpoint level (kg of substance equivalent) in Table 4 where specific midpoint categories results are displayed; then a damage assessment graph is presented for comparing the environmental toll of each Life Cycle stage in the different endpoint impact categories or areas of concern. The Life cycle stages have been divided into three groups: 1) construction phase including the production stage and transport of materials required for building the DH system; 2) operational phase including the energy use and operational processes for running a DH system; 3) building renovation accounting for the materials and its transport, for refurbishment at the end-user side. After analysing the life cycle stages, a damage assessment is shown in terms of Eco-indicator points, $\mathrm{kPt}$, in relation to the FU. This damage assessment presents result in the main four areas of concern evaluated within the IMPACT 2002+ methodology: human health, ecosystem quality, climate change and resources. Finally, within the parishes and scenarios evaluation, hotspots are identified by comparing the Life Cycle stages and their total environmental burden.

TABLE 4. Characterization RESUlts COMPARISON BETWEEN DH TECHNOLOGIES

\begin{tabular}{|c|c|c|c|c|}
\hline Impact category & Unit & 3GDH & 4GDH & Change \\
\hline Carcinogens & $\mathrm{kg} \mathrm{C}_{2} \mathrm{H}_{3} \mathrm{Cl}$ eq & 2595945 & 2596420 & 474 \\
\hline Non-carcinogens & $\mathrm{kg} \mathrm{C}_{2} \mathrm{H}_{3} \mathrm{Cl}$ eq & 12830261 & 12268175 & -562086 \\
\hline Respiratory inorganics & $\mathrm{kg} \mathrm{PM}_{2.5}$ eq & 608624 & 276023 & -332601 \\
\hline Ionizing radiation & Bq C-14 eq & $1.28 \mathrm{E}+09$ & $1.25 \mathrm{E}+09$ & $-2.99 \mathrm{E}+07$ \\
\hline Ozone layer depletion & $\mathrm{kg} \mathrm{CFC}-11 \mathrm{eq}$ & 12.3 & 10.3 & -2.0 \\
\hline Respiratory organics & $\mathrm{kg} \mathrm{C}_{2} \mathrm{H}_{4}$ eq & 116518 & 94036 & -22483 \\
\hline Aquatic ecotoxicity & $\mathrm{kg}$ TEG water & $9.71 \mathrm{E}+10$ & $9.25 \mathrm{E}+10$ & $-4.60 \mathrm{E}+09$ \\
\hline Terrestrial ecotoxicity & kg TEG soil & $3.43 \mathrm{E}+10$ & $3.26 \mathrm{E}+10$ & $-1.72 \mathrm{E}+09$ \\
\hline Terrestrial acid/nutri & $\mathrm{kg} \mathrm{SO}_{2}$ eq & 5794645 & 4625667 & -1168978 \\
\hline Land occupation & $\mathrm{m}^{2}$ org. arable & 95823050 & 40678584 & -55144466 \\
\hline Aquatic acidification & $\mathrm{kg} \mathrm{SO}_{2}$ eq & 950161 & 802406 & -147755 \\
\hline Aquatic eutrophication & $\mathrm{kg} \mathrm{PO}_{4} \mathrm{P}-\mathrm{lim}$ & 91312 & 89408 & -1904 \\
\hline Global warming & $\mathrm{kg} \mathrm{CO}_{2}$ eq & 85935081 & 74669357 & -11265724 \\
\hline Non-renewable energy & MJ primary & $1.56 \mathrm{E}+09$ & $1.38 \mathrm{E}+09$ & $-1.75 \mathrm{E}+08$ \\
\hline Mineral extraction & MJ surplus & 6846417 & 7056832 & 210415 \\
\hline
\end{tabular}

Implementation of Low Temperature District Heating system has proven to have an overall environmental benefit in almost all categories but carcinogens and mineral extraction, where the increase related to the development of a $4 \mathrm{GDH}$ system is in the order of $0.02 \%$ and $2.98 \%$, respectively. On the other hand, the respiratory inorganics category shows a $54.65 \%$ reduction, Respiratory organics and Terrestrial acidity have a $20 \%$ reduction and land occupation category has the largest decrease with a reduction in the required area for extracting raw materials of $55144466 \mathrm{~m}^{2}$, a $57.55 \%$ drop. The changes per impact category can be seen in Fig. 2. 


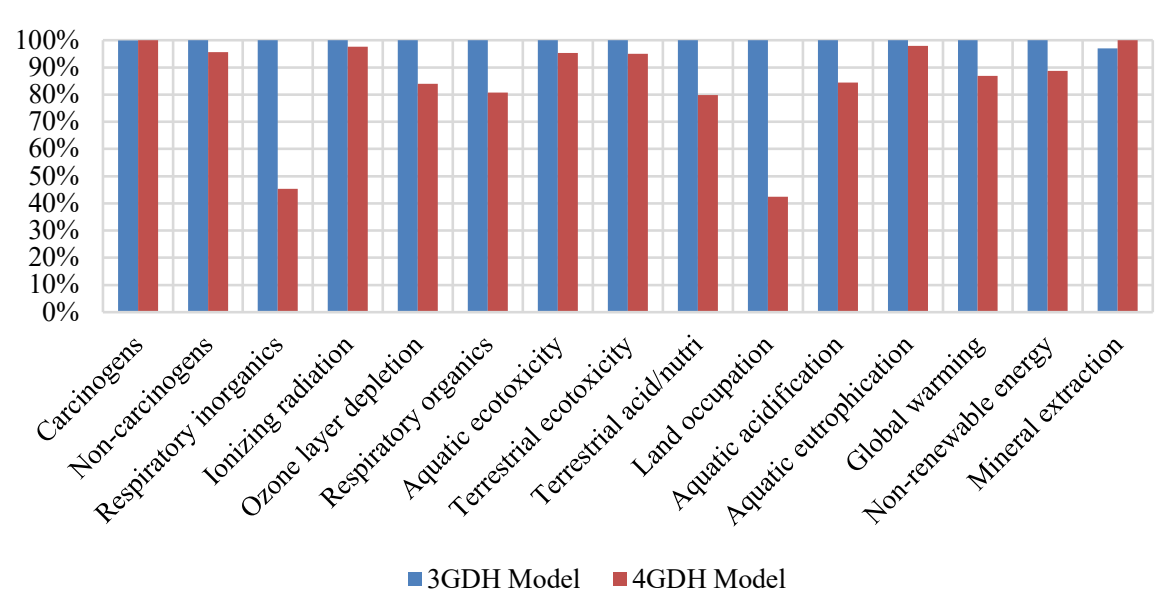

Fig. 2. Characterization comparison between impact categories.

The life cycle stages and their associated environmental toll is shown in Fig. 3, where the operational phase under the current circumstances ( $3^{\text {rd }}$ generation district heating system) is easily identified as the main hotspot among the stages. On the other hand, the refurbishment required on the end-user side has little impact when compared to other life cycle phases.

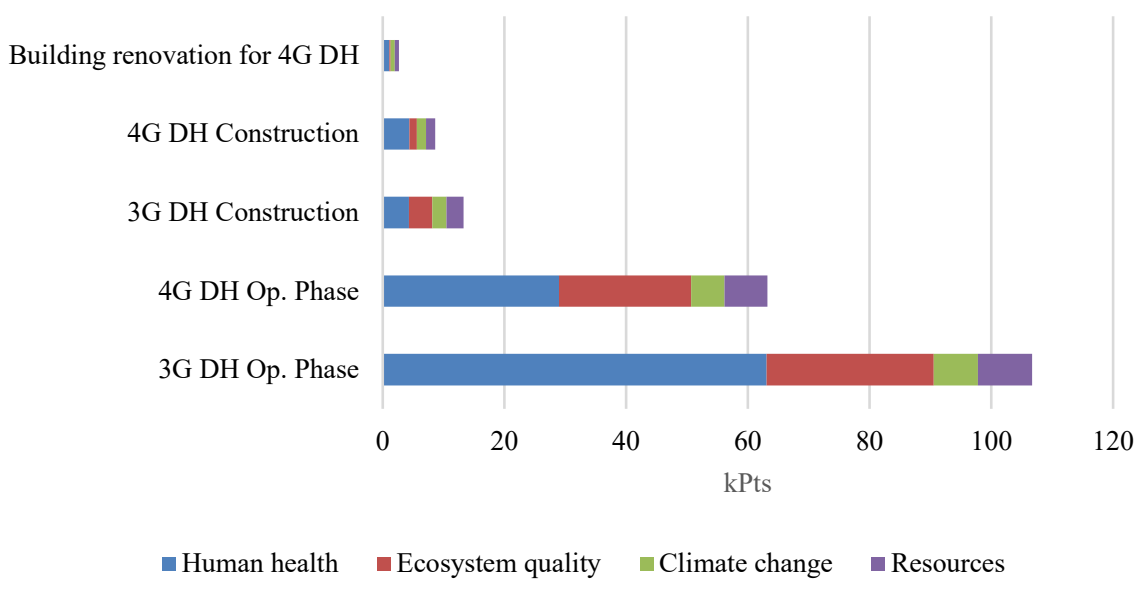

Fig. 3. Damage assessment for life cycle stages.

The aggregated difference at endpoint categories, or areas of concern, is shown in Fig. 4. In the human health area, the one with the highest environmental toll, the reduction of moving from a $3 \mathrm{GDH}$ to a $4 \mathrm{GDH}$ system, is equal to $50 \%$. The total environmental score for the human health area under the current conditions in Gulbene region, deliver $66.24 \mathrm{kPts}$ for the analysed FU, while under a $4 \mathrm{GDH}$ system the resulting score is $33.18 \mathrm{kPts}$. Although the reduction percentage in other areas are not as high as the observed for the human health one, still benefits from moving towards a 4GDH are found in the three remaining areas under the IMPACT 2002+ methodology. 
It is important to clear up the concept of a point (Pt) in the IMPACT 2002+ methodology. A point is equal to the average impact caused by a person in a specific category during one year in Europe, while on the contrary, for the human health category, a point represents the average impact on a person in the course of one year. Thus, if an impact of 3 points in climate change, ecosystem quality or resources is found, it would exemplify the average annual impact caused by 3 Europeans.

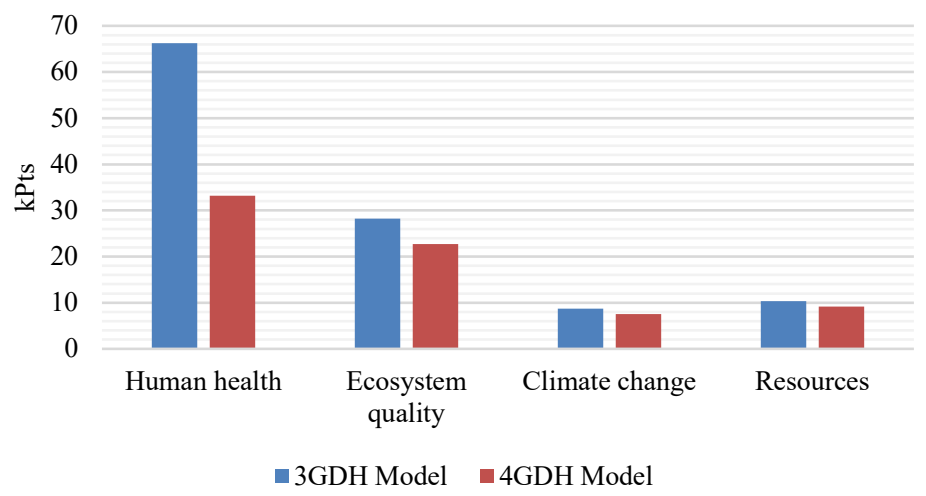

Fig. 4. Weighted damage assessment comparison at end point categories.

Finally, the total single score for each model is plotted in Fig. 5, where the combined results in each area of concern are presented. The $3 \mathrm{GDH}$ system gives a total score of $113.45 \mathrm{kPts}$, and the $4 \mathrm{GDH}$ system $72.62 \mathrm{kPts}$, showing a total reduction of $40.83 \mathrm{kPts}$, representing an environmental impact reduction of $36 \%$.

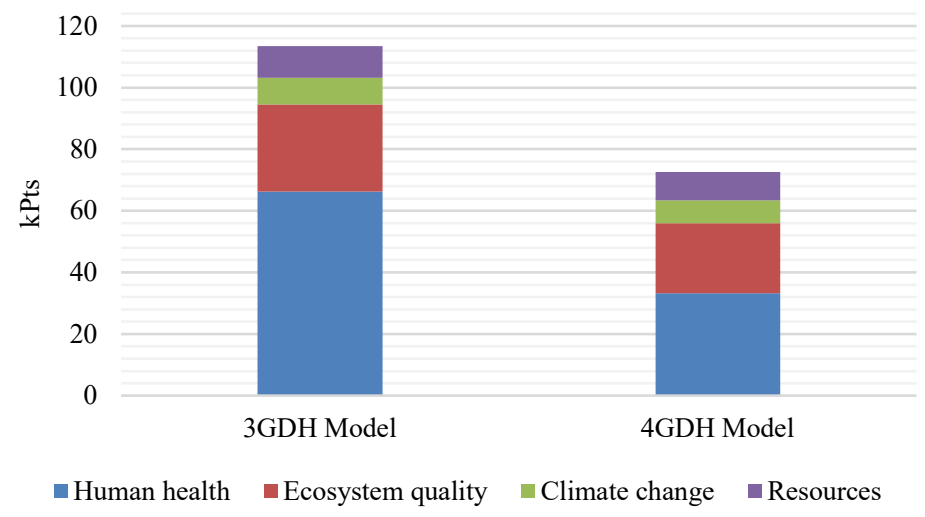

Fig. 5. Weighted damage assessment comparison at end point categories.

\section{Conclusions}

Results from the LCA undertaken in this study show the potential benefits in almost all impact categories recommended in [17], with only the mineral extraction category (represented as "MJ surplus", see Table 4) showing an actual negative impact of moving from the current district heating system running in the Gulbene region to a $4 \mathrm{GDH}$ system. This is 
due to the necessity of refurbishment in the buildings where a $4^{\text {th }}$ generation DH system is to be deployed, as materials required for it (see Table 3) represents an energy increase from the extractive activities, and to the fact that there are parishes where the thermal energy consumed during the heating season is nowadays being purchased from external companies but under the $4 \mathrm{GDH}$ scenario, the construction of new facilities and local heat production activities are considered.

The environmental benefit of implementing low-temperature district heating systems comes mainly from reduction in the amount of fuel required for operation and from moving from fossil non-renewable energies towards renewable ones as biomass for this case. The use of renewable energies is the key aspect in 4GDH systems, since it was determined from the results for the Lizums parish, that using fossil fuels, even for a low-temperature scenario, results in higher damage values to the resources and climate change areas than in other parishes where thermal energy is $100 \%$ obtained from renewable sources such as biomass.

The building refurbishment activity is another aspect to pay special attention to. The amount of materials required to lower the specific heat consumption per area depends on the current building insulation condition. If the area to refurbish is too large, and the initial specific heat consumption value is also high, the environmental impact from this activity could be quite large, even larger than the DH system construction itself (as it was identified during single LCA for the 4GDH scenarios in some parishes). However, if $3 \mathrm{GDH}$ systems are already operating in a municipality, the aggregated impact from undertaking refurbishment tasks in the buildings will be overlapped in the long term by the benefits of operating under a lower temperature profile when the heat is generated from biomass.

\section{ACKNOWLEDGEMENT}

This work is supported by the European Commission through the EU INTERREG Baltic Sea Region Project Number R063 Low Temperature District Heating for the Baltic Sea Region" (LowTEMP). The contents of this publication are the sole responsibility of the authors and can in no way be taken to reflect the views of the Riga Technical University or the European Commission. The authors would like to thank Mrs. Dagnija Blumberga, Director and professor at the Institute of Energy Systems and Environment for encouraging the development of this work.
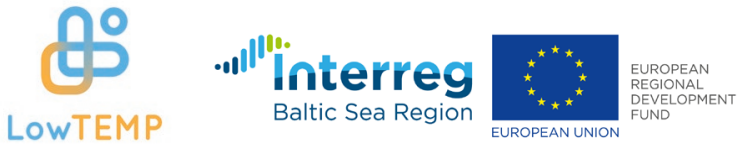

\section{REFERENCES}

[1] Wiltshire R. Advanced District Heating and Cooling (DHC) Systems. Woodhead Publishing, 2016.

[2] Saeima of the Republic of Latvia. "Sustainable Development Strategy of Latvia until 2030", 2010. [Online]. [Accessed 29.04.2020]. Available: https://www.pkc.gov.lv/sites/default/files/inline-files/LIAS_2030_en_1.pdf

[3] Mazhar A. R., Liu S., Shukla A. A state of art review on the district heating systems. Renewable and Sustainable Energy Reviews 2018:96:420-439. https://doi.org/10.1016/j.rser.2018.08.005

[4] Connolly D. et al. Heat roadmap Europe: Combining district heating with heat savings to decarbonise the EU energy system. Energy Policy 2014:65:475-489. https://doi.org/10.1016/j.enpol.2013.10.035

[5] European Climate Foundation. "Roadmap 2050", April 2010. [Online]. [Accessed 28.04.2020]. Available: https://www.roadmap2050.eu/attachments/files/Volume1_fullreport_PressPack.pdf

[6] Lake A., Rezaie B., Beyerlein S. Review of district heating and cooling systems for a sustainable future. Renewable and Sustainable Energy Reviews 2017:67:4147-425. https://doi.org/10.1016/j.rser.2016.09.061

[7] Thellufsen J. Z., Nielsen S., Lund H. Implementing cleaner heating solutions towards a future low-carbon scenario in Ireland. Journal of Cleaner Production 2019:214:377-388. https://doi.org/10.1016/j.jclepro.2018.12.303 
[8] Sernhed K., Lygnerud K., Werner S. Synthesis of recent Swedish district heating research. Energy 2018:151:126-132. https://doi.org/10.1016/j.energy.2018.03.028

[9] Vigants E., Prodanuks T., Vigants G., Veidenbergs I., Blumberga D. Modelling of Technological Solutions to 4th Generation DH Systems. Environmental and Climate Technologies 2017:20(1):5-23. https://doi.org/10.1515/rtuect2017-0007

[10] Bolonina A., Bolonins G., Blumberga D. Analysis of the Impact of Decreasing District Heating Supply Temperature on Combined Heat and Power Plant Operation. Environmental and Climate Technologies 2015:14(1). https://doi.org/10.1515/rtuect-2014-0013

[11] Brange L., Englund J., Sernhed K., Thern M., Lauenburg P. Bottlenecks in district heating systems and how to address them. Energy Procedia 2017:116:249-259. https://doi.org/10.1016/j.egypro.2017.05.072

[12] Curtis J., McCoy D., Aravena C. Heating system upgrades: The role of knowledge, socio-demographics, building attributes and energy infrastructure. Energy Policy 2018:120:183-196. https://doi.org/10.1016/j.enpol.2018.05.036

[13] Rebitzer G., Ekvall T., Frischknech R., Hunkeler D., Norris G., Rydberg T., Schmidt W., Suh S., Weidema B., Pennington D. Life cycle assessment Part 1: Framework, goal and scope definition, inventory analysis, and applications. Environment International 2004:30(5):701-720. https://doi.org/10.1016/j.envint.2003.11.005

[14] Buxel H., Esenduran G., Griffin S. Strategic sustainability: Creating business value with life cycle analysis. Business Horizons 2015:58(1):109-122. https://doi.org/10.1016/j.bushor.2014.09.004

[15] Bartolozzi I., Rizzi F., Frey M. Are district heating systems and renewable energy sources always an environmental win-win solution? A life cycle assessment case study in Tuscany, Italy. Renewable and Sustainable Energy Reviews 2017:80:408-420. https://doi.org/10.1016/j.rser.2017.05.231

[16] Jolliet O., Charles M. M. R., Humbert S., Payet J., Rebitzer G., Rosenbaum R. IMPACT 2002+: A New Life Cycle Impact Assessment Methodology. International Journal on LCA 2003:8(6):324-330. https://doi.org/10.1007/BF02978505

[17] ISO. ISO 14044:2006 Environmental management — Life cycle assessment — Requirements and guidelines, 2006.

[18] Oliver-Solà J., Gabarrell X., Rieradevall J. Environmental impacts of the infrastructure for district heating in urban neighbourhoods. Energy Policy 2009:37(11):4711-4719. https://doi.org/10.1016/j.enpol.2009.06.025

[19] Bartolozzia I., Rizzib F., Frey B. Are district heating systems and renewable energy sources always an environmental win-win solution? A life cycle assessment case study in Tuscany, Italy. Renewable and Sustainable Energy Reviews 2017:80:408-420. https://doi.org/10.1016/j.rser.2017.05.231

[20] Ristimaki M., Saynajoki A., Heinonen J., Junnila S. Combining life cycle costing and life cycle assessment for an analysis of a new residential district energy system design. Energy 2013:63:168-179. https://doi.org/10.1016/j.energy.2013.10.030

[21] Humbert S., Schyver A. D., Bengoa X., Margni M., Jolliet O. IMPACT 2002+: User guide, Quantis, 2012.

[22] Feofilovs M., Pakere I., Romagnoli F. Life Cycle Assessment of Different LowTemperature District Heating Development. Environmental Climate Technologies 2019:23(2):272-290. https://doi.org/10.2478/rtuect-2019-0068

[23] Ekodoma. Strategy for low temperature district heating system implementation in Gulbene municipality. Gulbene, 2019.

[24] Stephan A., Crawford R. H., Myttenaere K. D. A comprehensive assessment of the life cycle energy demand of passive houses. Applied Energy 2013:112:23-34. https://doi.org/10.1016/j.apenergy.2013.05.076

[25] Angelis E. De, Dotelli G., Pittau F., Torre A. La, Porcino C., Pansa G., Villa N. LCA and LCC based Energy Optimization of Building Renovation Strategies. In SB13 GRAZ Sustainable Building Conference 2013, Graz, 2013.

[26] Bull J., Gupta A., Mumovic D., K. J. Life cycle cost and carbon footprint of energy efficient refurbishments to 20th century UK school buildings. International Journal of Sustainable Built Environment 2014:3(1):1-17. https://doi.org/10.1016/j.ijsbe.2014.07.002

[27] Pakere I. Interviewee. Building energy audit and renovation in the Gulbene Area. [Interview]. 21 November 2019. 